\title{
Cellular effects of AP102, a somatostatin analog with balanced affinities for the hSSTR2 and hSSTR5 receptors
}

\author{
Jeremy Streuli ${ }^{\mathrm{a}}$, Alan G. Harris ${ }^{\mathrm{c}}$, Cecilia Cottiny ${ }^{\mathrm{a}}$, Florent Allagnat ${ }^{\mathrm{b}}$, Adrian F. Daly ${ }^{\mathrm{c}}$, \\ Eric Grouzmann ${ }^{\mathrm{a}, 1}$, Karim Abid ${ }^{\mathrm{a}, *, 1}$ \\ ${ }^{a}$ Service of Clinical Pharmacology, Catecholamine and Peptides Laboratory, Centre Hospitalier Universitaire Vaudois (CHUV), 1001 Lausanne, Switzerland \\ ${ }^{\mathrm{b}}$ Department of Vascular Surgery, CHUV, University of Liège, Domaine Universitaire du Sart-Tilman, 4000 Liège, Belgium \\ ${ }^{\mathrm{c}}$ Department of Endocrinology, Centre Hospitalier Universitaire de Liège, University of Liège, Domaine Universitaire du Sart-Tilman, 4000 Liège, Belgium
}

\section{A R T I C L E I N F O}

\section{Keywords:}

Somatostatin

Analogs

Receptors

Neuroendocrine

Tumors

Therapy

\begin{abstract}
A B S T R A C T
Background: Somatostatin analogs (SSAs) are first-line medical therapy for the treatment of acromegaly and neuroendocrine tumors that express somatostatin receptors (SSTR). Somatostatin suppresses secretion of a large number of hormones through the stimulation of the five SSTR. However, unbalanced inhibition of secretion as observed with the highly potent SSAs pasireotide causes hyperglycaemia mainly by inhibiting insulin secretion. In contrast, AP102 a new SSAs has neutral effect on blood glucose while suppressing GH secretion. Our objective was to establish the cellular effects of AP102 on SSTR2 and SSTR5 that may explain the differences observed between AP102 and other SSAs.

Methods: We compared the binding and agonist activity of AP102 with somatostatin-14, octreotide and pasireotide in HEK293 cells transfected with human SSTR2 and SSTR5 receptors. SSAs signal transduction effects (cAMP concentrations) were measured in forskolin-treated cells in the presence of SSAs. Proliferation and apoptotic effects were determined and binding assays were performed using ${ }^{125}$ I- somatostatin- 14.

Results: AP102 has comparable affinity and agonist effect to octreotide at SSTR2 (IC50's of $112 \mathrm{pM}$ and $244 \mathrm{pM}$, respectively; EC50's of $230 \mathrm{pM}$ and $210 \mathrm{pM}$, respectively) in contrast to pasireotide that exhibits a 12-27 fold higher IC50 (3110 pM) and about 5-fold higher EC50 (1097 pM). At SSTR5, AP102 has much higher affinity and stimulating effect than octreotide (IC50's of 773 pM and 16,737 pM, respectively; EC50's of 8526 pM and 26,800 $\mathrm{pM})$, and an intermediate affinity and agonist effect between octreotide and pasireotide. AP102, octreotide and pasireotide have variable anti-proliferative effects on HEK cells transfected with SSTR2 and SSTR5.

Conclusion: AP102 is a new SSA that better reduces signaling at SSTR2 than SSTR5 and prevents cell proliferation at both receptors. The euglycaemic effect of AP102 observed in preclinical studies may be related to this intermediate agonistic potency between pasireotide and octreotide at SSTR2 and SSTR5.
\end{abstract}

\section{Introduction}

Somatostatin analogs (SSAs), also known as somatostatin-receptor ligands (SRL), are used in the treatment of diseases like acromegaly, caused mostly to chronic growth hormone (GH) hypersecretion from a pituitary tumor (Katznelson et al., 2014; Öberg and Lamberts, 2016). They are also used in the management of neuroendocrine tumors (NET) that secrete large amounts of bioactive neurotransmitters (e.g. catecholamines or serotonin) (Eisenhofer et al., 2012; Franscini et al., 2015; Modlin et al., 2016). Pituitary tumors and NET express somatostatin receptors (SSTR) and activation of these receptors can have anti-secretory and anti-proliferative effects (Körner, 2016; Csaba and Dournaud, 2001). These properties led to the development of octreotide and lanreotide that are SSTR2 specific, while pasireotide is an agonist with activity at multiple SSTRs, predominantly SSTR5, but with a lower SSTR2 affinity than first generation compounds (Öberg and Lamberts, 2016; Colao et al., 2016). SSTR2-specific compounds have incomplete efficacy in the clinical setting, presumably due to variable expression SSTR2 by tumors and their low affinity for other biologically important receptors like SSTR5 (Paragliola et al., 2017). Pasireotide has greater efficacy than octreotide in acromegaly, but this is associated with the development of hyperglycemia and diabetes via its strong SSTR5

\footnotetext{
* Corresponding author at: Service of Clinical Pharmacology, Catecholamine and Peptides Laboratory, Hospital Nestlé, Av Pierre Decker 5, Centre Hospitalier Universitaire Vaudois (CHUV), 1011 Lausanne, Switzerland.

E-mail address: Karim-Alexandre.Abid@chuv.ch (K. Abid).

${ }^{1}$ These two authors shared the senior authorship for this paper.
} 
activity that inhibits insulin secretion (McKeage, 2015; Silverstein, 2016).

AP102 is a disulfide-bridged iodinated octapeptide that contains synthetic amino acids selected from a library of 10 SSAs (identified as peptide \#9 in reference (Moore et al., 2005)). Receptor binding studies conducted using membranes from rat colon carcinoma cells (CC531 cells) (for hSSTR2) and Chinese hamster ovary (CHO)-K1 cells (for hSSTRs 1, 3, and 5), stably expressing individual human somatostatin receptor subtypes established sub-nanomolar affinity for both the SSTR2 and SSTR5 receptors (Moore et al., 2005). Moreover, AP102 exhibited virtually identical inhibitory effects on GH and prolactin release as native somatostatin-14 (SS14) in cultured pituitary cells obtained from female Wistar rats (Moore et al., 2005). When AP102 was administered to healthy male rats it acutely reduced growth hormone secretion, but did not result in hyperglycemia when given acutely or chronically (Tarasco et al., 2017). Our results demonstrate the potential for AP102 to fill the gap left by other SSAs in treating conditions associated with hormonal hypersecretion. We postulated that a different affinity and cellular effect at the SSTR2 and SSTR5 receptors with AP102 as compared to pasireotide could explain the absence of diabetogenic effects, while permitting relevant effects on hormonal suppression.

The aim of this study was to compare AP102 with octreotide and pasireotide regarding cellular effects, including cell signal transduction, cell proliferation and toxicity using stably-transfected HEK 293 cells expressing hSSTR2 and hSSTR5.

\section{Materials and methods}

\subsection{Compounds}

AP102 was synthesized as described (Moore et al., 2005). Somatostatin-14 (also known as somatotropin release inhibiting factor 14 or SRIF-14) was purchased from Polypeptide laboratories (Strasbourg, France) and octreotide was purchased from Sigma (Sigma-Aldrich, Buchs, Switzerland). Pasireotide (also known as SOM230) was obtained from a vial of Signifor ${ }^{\circledR}$ (Novartis, Basel).

\subsection{HEK-293 cell lines expressing hSSTR2 and hSSTR5}

Plasmids encoding the human somatostatin receptors 2 and 5 transgenes were obtained from Missouri S\&T cDNA resource center: http://www.cdna.org hSSTR2: ref. number hSSTR20TN00; hSSTR5: ref. number hSSTR50TN00. Both transgenes contained an N-terminal 3xHA-tag and were cloned into a pcDNA3.1 + vector. Transfections were performed with lipofectamine 2000 (Invitrogen, Luzern, Switzerland) according to the manufacturer's protocol. After transfection, cells were cultivated in DMEM supplemented with $10 \%$ fetal bovine serum, $100 \mathrm{U} / \mathrm{ml}$ penicillin $\mathrm{G}$ and $100 \mu \mathrm{g} / \mathrm{ml}$ streptomycin sulfate (Life Technology, Zug, Switzerland) and incubated in a humidified 5\% $\mathrm{CO}_{2}$ incubator at $37^{\circ} \mathrm{C}$. Positive clones were selected with $500 \mu \mathrm{g} / \mathrm{ml}$ of G418 (Gentaur, Zürich, Switzerland) and tested for the presence of SSTR transgenes as follows: cells were lyzed in a buffer containing PBS with $0.5 \%$ Triton-X100 and protease inhibitor with EDTA (Roche, Basel, Switzerland). Cell lyzates were fractionated with SDS-PAGE under reducing conditions using precast gels (Bio-Rad, Reinach, Switzerland), proteins were electroblotted onto nitrocellulose membrane (Bio-Rad) and probed with anti-SSTR antibodies. SSTR proteins were immuno-detected using rabbit anti-SSTR2 (AB 134152, Abcam, Cambridge, United Kingdom) and anti-SSTR5 (AB 109495, Abcam) monoclonal antibodies. A monoclonal antibody against $\beta$-actin was obtained from Sigma (A-5441). Secondary HRP-conjugated antibodies (\#170-6515) were purchased from Bio-Rad (Reinach, Switzerland). Immunoreactive bands were revealed by a chemiluminescence assay (Western lightning plus-ECL, PerkinElmer, Schwerzenbach, Switzerland) and the signal was processed by a digital imaging analyzer
(ImageQuant LAS-4000, General Electric, Glattbrugg, Switzerland). Expression of hSSTR2 and hSSTR5 was successfully detected in transfected cells (Fig. S1).

\subsection{Binding assays}

Cells were harvested at $80 \%$ confluency in a $145 \mathrm{~cm}^{2}$ petri dishes, washed with $20 \mathrm{ml}$ cold PBS, scraped with $3 \mathrm{ml}$ of cold harvesting buffer (HB), and $1.25 \mathrm{ml} \mathrm{HB}$ was used to rinse the petri dish. The $\mathrm{HB}$ composition was as follows: $50 \mathrm{mM}$ hepes $\mathrm{pH} 7.5,1 \mathrm{mM} \mathrm{MgCl}_{2}, 2.5 \mathrm{mM}$ $\mathrm{CaCl}_{2}, 0.50 \%$ BSA (Sigma-Aldrich), $150 \mathrm{mM} \mathrm{NaCl}, 2.5 \mu \mathrm{gr} / \mathrm{ml}$ Aprotinin (Applichem, Darmstadt, Germany) and $250 \mu \mathrm{g} / \mathrm{ml}$ Bacitracin (SigmaAldrich). Cells were centrifuged at $1000 \mathrm{rpm}$ for $2 \mathrm{~min}$ after which the pellet was re-suspended ( $1 \mathrm{ml} /$ dish with $\mathrm{HB}$ and 5\% DMSO) and samples were aliquoted at $150 \mu \mathrm{l}$ and stored at $-80^{\circ} \mathrm{C}$. Protein concentration was quantified at $450 \mu \mathrm{g} / \mathrm{ml}$ for hSSTR2 and $700 \mu \mathrm{g} / \mathrm{ml}$ for hSSTR5 with a BCA test (Thermofisher, Basel, Switzerland).

SS14 and tested SSAs (AP102, octreotide and pasireotide) were diluted in binding buffer (BB) containing $5 \mathrm{mM}$ Hepes pH 7.5, $5 \mathrm{mM}$ $\mathrm{MgCl} 2,2 \mathrm{mM} \mathrm{CaCl} 2,0.10 \% \mathrm{BSA}, 2.5 \mu \mathrm{gr} / \mathrm{ml}$ aprotinin and distributed $(150 \mu \mathrm{l})$ in duplicate Eppendorf tubes. To this was added 15,000 cpm of ${ }^{125} \mathrm{I}-\mathrm{SS} 14(100 \mu \mathrm{l})(10 \mu \mathrm{Ci}, 2200 \mathrm{ci} / \mathrm{mmol}$, PerkinElmer $)$ diluted in BB and finally the cell membrane preparations were added (diluted in $50 \mu \mathrm{l}$ of BB and corresponding to $4.5 \mu \mathrm{g}$ and $7 \mu \mathrm{g}$ of protein for hSSTR2 and hSSTR5, respectively) to reach a total incubation volume of $300 \mu$ l. These underwent rolling incubation for $45 \mathrm{~min}$ at room temperature and cell membranes were pelleted after $2 \mathrm{~min}$ of centrifugation at $14000 \mathrm{rpm}$ in a microfuge. The supernatant was discarded and cell membranes were shaken and washed with $300 \mu \mathrm{l}$ BB before another round of centrifugation and supernatant removal. Membrane pellets were cut from the bottom of the Eppendorf tubes and were placed in a tube for counting in a gamma radioactivity counter (GammaCounter Wizard 1470-020, PerkinElmer) for $1 \mathrm{~min}$.

Non-specific binding was determined in presence of $1 \mu \mathrm{M}$ of SS14 and specific binding corresponding to the difference between total binding (cpm measured in tube without competitor) and non-specific binding.

\section{4. cAMP accumulation experiments}

HEK-hSSTR2 or HEK-hSSTR5 cells were seeded in 24-well plates at 375,000 cells per well and grown in DMEM supplemented with $10 \%$ fetal bovine serum for $48 \mathrm{~h}$ in a humidified $5 \% \mathrm{CO}_{2}$ incubator at $37{ }^{\circ} \mathrm{C}$. Culture medium was then removed, and $200 \mu \mathrm{l}$ of fresh serum-free DMEM containing $0.5 \mathrm{mM}$ 3-isobutyl-1-methylxanthine (buffer A; Sigma-Aldrich) was added to each well. After five minutes' incubation at $37^{\circ} \mathrm{C}$ in $5 \% \mathrm{CO} 2,100 \mu \mathrm{l}$ of buffer A containing varying concentrations of SSAs was added. In order to stimulate adenylate cyclase, $100 \mu \mathrm{l}$ of fresh buffer A containing $40 \mu \mathrm{M}$ forskolin (Sigma-Aldrich) was added and the cells were further incubated for $20 \mathrm{~min}$ at $37^{\circ} \mathrm{C}$. The cell medium was removed and $200 \mu \mathrm{l}$ of $0.1 \mathrm{M} \mathrm{HCl}$ were added to each well to ensure stabilization of cAMP and allow its extraction. Cells were dissociated by pipetting up and down until suspension was homogeneous. The lysate was transferred to a centrifuge tube and washed thoroughly with $100 \mu \mathrm{l}$ of $0.1 \mathrm{M} \mathrm{HCl}$ to recover remaining traces of sample; thereafter the extract was centrifuged at $14000 \mathrm{rpm}$ for $10 \mathrm{~min}$ $(200 \mu \mathrm{l}+100 \mu \mathrm{l})$. The supernatants were dried by lyophilisation and reconstituted in $100 \mu \mathrm{l}$ of $\mathrm{HCl} 0.1 \mathrm{M}$ before assays. cAMP accumulation was measured using the cAMP direct immunoassays kit (colorimetric, K371; BioVision) according to the manufacturer's protocol. The maximum of forskolin-stimulated cAMP formation was defined in the presence of $10 \mu \mathrm{M}$ forskolin and the maximum inhibition was obtained using $100 \mathrm{nM}$ of SS14. EC50's were calculated using GraphPad Prism 6 software based on 3-4 separate curves using five concentrations of ligands in duplicate (i.e., two separate wells per concentration) (Fig. S2). 


\subsection{Cell proliferation assays}

HEK, HEK-hSSTR2 and HEK-hSSTR5 transfected cells were seeded with $100 \mu$ of DMEM supplemented with $10 \%$ fetal bovine serum in 96 well plates $\left(3 \times 10^{4}\right.$ cells/well). After $24 \mathrm{~h}$ in culture, cells were treated with $100 \mu \mathrm{l}$ of medium and SS14 or somatostatin analogs at $2 \mu \mathrm{M}(1 \mu \mathrm{M}$ final concentration) for $48 \mathrm{~h}$. The control group only had medium added. Cell number was evaluated by the addition of MTT solution [3(4,5-dimethylthiazol-2-yl)-2,5-diphenyltetrazolium bromide] $(0.5 \mathrm{mg}$ / $\mathrm{ml}$ final concentration, Merck, Zug, Switzerland) and plates were incubated in a humidified $5 \% \mathrm{CO}_{2}$ incubator at $37^{\circ} \mathrm{C}$ for two hours. The culture medium was then carefully removed and the plates were fan dried for $20 \mathrm{~min}$. Precipitated formazan crystals were solubilized in $150 \mu \mathrm{l}$ DMSO. Plates were agitated on orbital shaker for $20 \mathrm{~min}$ until complete dissolution of the crystals. Absorbance was measured at a wavelength of $560 \mathrm{~nm}$ with an ELISA reader (Mithras LB940, Berthold Technologies, Regensdorf, Switzerland). MTT signal (optic density) over cell number was assessed and gave a linear response from 20,000 to 55,000 cells (data not shown). Each assay was performed in quadruplicate at least five times. In each experiment, the mean absorbance observed for the control group was rated as $100 \%$ of proliferation, and each value for each treatment was compared to this value.

\subsection{Assessment of cell viability}

The percentage of viable and dead HEK, HEK-hSSTR2 and HEKhSSTR5 transfected cells was determined using the DNA-binding dyes Propidium Iodide (PI, $5 \mu \mathrm{g} / \mathrm{ml}$ ) and Hoechst 33,342 (HO, $5 \mu \mathrm{g} / \mathrm{ml}$, Sigma-Aldrich) as previously described (Allagnat et al., 2013). The cells were examined by inverted fluorescence microscopy (Nikon Eclipse TS100, Nikon Instruments, Egg, Switzerland). Thapsigargin $(5 \mu \mathrm{M}$, Sigma-Aldrich) was used as a positive control to induce cell death (Allagnat et al., 2013). A minimum of three visual fields comprising at least 200 cells each were counted for each condition by two independent operators, one of them unaware of the sample identity. The score reflected number of dead cells as a percentage of total cells in the field observed.

\subsection{Statistical analysis}

The statistical differences between the treatment groups against the control group were assessed by an ANOVA followed by a Dunnett's test for multiple comparisons. Statistical analyses were performed using GraphPad Prism 6 software. The differences were considered statistically significant at $P \leq 0.05$. Curve fitting and binding parameters were calculated using the One Site - Fit logIC50 package of GraphPad Prism 6 software (Fig. S3).

\section{Results}

\section{1. cAMP accumulation}

It has been previously demonstrated that hSSTR2 and hSSTR5 agonists cause inhibition of adenylyl cyclase via coupling to Gi proteins, as reviewed by Eigler and Ben-Shlomo (2014). We determined the concentration (EC50) needed of SS14, AP102, octreotide and pasireotide to inhibit $50 \%$ of the forskolin-stimulated cAMP production (Table 1 and Fig. S2). EC50's for SS14 on hSSTR2 and hSSTR5 expressing cells were 230 and $1860 \mathrm{pM}$, respectively. Octreotide inhibited cAMP production potently in SSTR2 expressing cells (EC50: $210 \mathrm{pM}$ ), but in keeping with the low SSTR5 binding affinity octreotide had a very low agonist activity in hSSTR5 cells (EC50: 26800 pM). Pasireotide was more potent in hSSTR5 than hSSTR2 expressing cells (EC50 598 and $1097 \mathrm{pM}$, respectively). The EC50 of AP102 on hSSTR2 cell line was $288 \mathrm{pM}$, whereas it had an intermediate potency between pasireotide and octreotide in hSSTR5 expressing cells (8526 pM).
Table 1

Summary of EC50's for each compound (in pM) with confidence intervals based on 3 to 4 separate experiments performed in duplicate. SS14: somatostatin-14.

\begin{tabular}{|c|c|c|c|c|}
\hline & \multicolumn{2}{|l|}{ SSTR2 } & \multicolumn{2}{|l|}{ SSTR5 } \\
\hline & $\begin{array}{l}\text { EC50 } \\
(\mathrm{pM})\end{array}$ & $\begin{array}{l}\text { 95\% confidence } \\
\text { intervals (pM) }\end{array}$ & EC50 (pM) & $\begin{array}{l}95 \% \text { confidence } \\
\text { intervals }(\mathrm{pM})\end{array}$ \\
\hline SS14 & 230 & 86 to 616 & 1860 & 770 to 4487 \\
\hline AP102 & 288 & 124 to 667 & 8526 & 3751 to 19,380 \\
\hline Octreotide & 210 & 122 to 358 & 26,800 & 8083 to 88,500 \\
\hline Pasireotide & 1097 & 479 to 2500 & 598 & 211 to 1696 \\
\hline
\end{tabular}

\subsection{Cell proliferation}

Apart from controlling hormone-mediated symptoms, SSAs have long been demonstrated to act as antiproliferative agents. We therefore monitored the cell proliferation effects of AP102 as compared with pasireotide and octreotide. Cell proliferation was unaffected by the test compounds in non-SSTR-transfected control HEK cells. SS14 led to a $5.8 \%$ and $15.6 \%$ inhibition of proliferation in SSTR2 and SSTR5-expressing HEK cells, respectively, versus control $(P \leq 0.01$; Fig. 1 and Table 2). AP102 led to significant reductions in proliferation in both SSTR2 $(8.1 \%)$ and SSTR5 $(12.7 \%)$ expressing HEK cells $(P<0.0001)$. Pasireotide reduced proliferation in SSTR2-expressing cells by $11.2 \%$ and in SSTR5 expressing cells by $13.4 \%(P<0.0001$ for both). In contrast, octreotide led to an only $3.7 \%$ decrease in proliferation versus control in the SSTR2 expressing cells $(P=$ n.s.), while reducing proliferation by $5.8 \%(P=0.006)$ in SSTR5. Inhibition of cell proliferation in hSSTR2 cells had the following rank order of potency: pasireotide $>$ AP102 $>$ SS14 $>>$ octreotide. In hSSTR5 expressing cells the order of potency was SS14 $>$ pasireotide $=$ AP102 $>$ octreotide.

\subsection{Toxicity and cell viability}

Neither SS14 nor any of the SSAs tested had toxic effects (necrosis or apoptosis) on control or SSTR expressing HEK cells (Fig. 2).

\subsection{Binding}

AP102 exhibited a subnanomolar affinity toward hSSTR2 and hSSTR5 receptors (Table 3). SS14 had a twofold higher affinity than AP102 for hSSTR2 (112 vs. 283 pM, respectively) and hSSTR5 (350 vs $773 \mathrm{pM})$, respectively. Pasireotide exhibited the highest affinity for hSSTR5 when compared to SS14 and AP102 (IC50: 200 pM) but the lowest of all the tested compounds for hSSTR2 (IC50: $3110 \mathrm{pM}$ ). As expected, octreotide had a low binding affinity for hSSTR5 (IC50: $16737 \mathrm{pM}$ ) while having a similar IC50 at SSTR2 versus AP102 (244 vs 283 pM, respectively; Table 3 and Fig. S3).

\section{Discussion}

AP102 signal transducing tests showed that cAMP accumulation EC50 for SS14 at hSSTR2 and hSSTR5 receptors were 230 and 1860 pM, respectively, which is similar to values reported in the literature at 240-600 pM (Schmid and Schoeffter, 2004; Peng et al., 2014; Grant et al., 2008; Lesche et al., 2009) and 320-1400 pM (Schmid and Schoeffter, 2004; Grant et al., 2008; Lesche et al., 2009), respectively. In agreement with Schmid and Schoeffter (Schmid and Schoeffter, 2004), octreotide is particularly potent at the hSSTR2 receptor with an EC50 of 210 pM but exhibits very low agonist activity on the hSSTR5 receptor with an EC50 of $26,800 \mathrm{pM}$; this is in accordance with values reported in other studies, ranging from 20,190 to 87,000 pM (Schmid and Schoeffter, 2004; Lesche et al., 2009). Pasireotide is more potent at hSSTR5 than hSSTR2 with EC50 values of 598 and 1097 pM, respectively, which is in the reported ranges from other studies (SSTR5: 


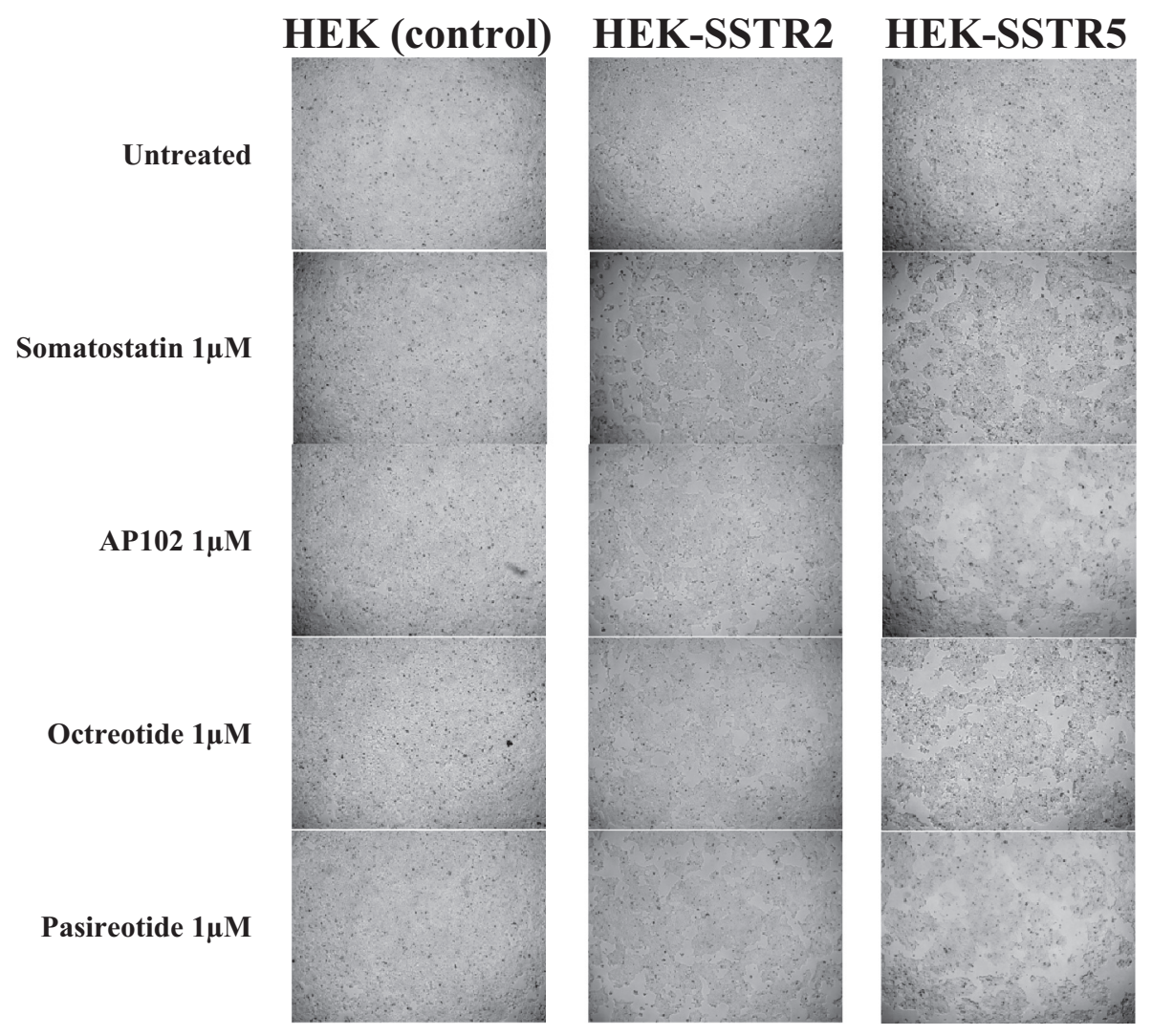

Fig. 1. Representative pictures of the effects of each compound on proliferation of HEK cells expressing SSTR2 and SSTR5.

Table 2

Inhibition of cell proliferation upon incubation with somatostatin-14 (SS14) and somatostatin analogs. Values are expressed as percentages compared with control (non treated cells).

\begin{tabular}{llll}
\hline & Mean diff.in \% & $95 \%$ CI of diff. & Adjusted $P$ value \\
\hline SSTR2 & & & \\
Octreotide $v$ s. control & -3.7 & 0.8 to -8.2 & 0.136 \\
Pasireotide $v$ s. control & -11.2 & -6.5 to -16.0 & $<0.0001$ \\
AP102 vs. control & -8.1 & -3.5 to -12.6 & $<0.0001$ \\
SS14 vs. control & -5.8 & -1.1 to -10.5 & 0.01 \\
SSTR5 & & & \\
Octreotide $v$ s. control & -5.8 & -1.3 to -10.4 & 0.006 \\
Pasireotide $v s$. control & -13.4 & -8.6 to -18.1 & $<0.0001$ \\
AP102 vs. control & -12.7 & -8.1 to -17.2 & $<0.0001$ \\
SS14 vs. control & -15.6 & -9.2 to -21.9 & $<0.0001$ \\
HEK-control & & & \\
Octreotide $v$ s. control & 0.4 & 4.6 to -3.7 & 0.99 \\
Pasireotide $v s$. control & -1.4 & 2.9 to -5.6 & 0.85 \\
AP102 $v s$. control & 3.9 & 8.2 to -0.4 & 0.09 \\
SS14 vs. control & -0.5 & 3.7 to -4.8 & 0.99 \\
\hline
\end{tabular}

550-580 pM; SSTR2: 390-1780 pM) (Grant et al., 2008; Bruns et al., 2002). The EC50 of AP102 for hSSTR2 was found to be $288 \mathrm{pM}$ (close to SS14) and 3.8-fold more potent than pasireotide. In fact, octreotide is 5.2 fold more potent than pasireotide at hSSTR2 (as previously shown: 4.9-6.5 fold (Schmid and Schoeffter, 2004; Lesche et al., 2009)), whereas octreotide has only a 27\% lower EC50 than AP102 for hSSTR2. AP102 shows a three-fold greater signal transduction potency when compared to octreotide and an intermediate potency between octreotide and pasireotide. AP102 exhibits unique agonist properties on hSSTR2 and hSSTR5 allowing a higher transducing effect on hSSTR2 cell line than pasireotide together with stimulation of hSSTR5. Previous data regarding binding activity of SSAs agonists (Moore et al., 2005) were reported on SSTR2 and SSTR5 receptors stably expressed in murine cells of different origin. We have therefore performed all experiments using a single human cell line to obtain reliable and comparable data and to exclude cell specificity that could modulate cellular effects and binding of the ligand.

Binding experiments shows that AP102 binds to the somatostatin receptors 2 and 5 (hSSTR2/5) with high affinity and selectivity, resulting in 50\% inhibition of the binding of iodinated SS14 at subnanomolar concentrations. These concentrations are similar to those reported by Moore et al. (2005) for hSSTR5 (773 pM vs 650 pM, peptide \#9 in (Moore et al., 2005)), while being twofold lower for hSSTR2 $(283 \mathrm{pM} v s 630 \mathrm{pM})$. These differences may be due to the binding assays having been performed on membranes derived from a different cell line (CC531 instead of HEK cells) transfected with individual human somatostatin receptors hSSTR2 and hSSTR5. Similarly, we found threefold higher IC50 for pasireotide than Bruns et al. (2002) (3110 pM vs $1000 \mathrm{pM}$ ) for hSSTR2 and identical affinity (200 pM $v s 160 \mathrm{pM})$ for hSSTR5, again while using distinct transfected cell lines. As expected, octreotide has high affinity for the hSSTR2 and weakly binds to hSSTR5 (relative hSSTR5/2 affinity ratio: 69). This is closer to what was observed by Schmid and Schoeffter (Schmid and Schoeffter, 2004) with a relative affinity ratio of 17 as compared with Moore et al. (IC50: $20 \mathrm{pM}$ and 21,800 pM, respectively) where a relative affinity ratio of 1090 was reported. The binding characteristics of AP102 at hSSTR5 are comparable to those of native SS14 (773 pM and $350 \mathrm{pM}$ respectively) and 22-fold more potent than octreotide. This increased affinity of AP102 compared to octreotide towards hSSTR5 could aid in promoting antiproliferative effects since hSSTR2 and hSSTR5 are co-expressed in neuroendocrine tumors and cooperate to suppress hormone action (Theodoropoulou and Stalla, 2013).

SSAs inhibited cell proliferation of HEK cells stably expressing hSSTR2 and hSSTR5. Although octreotide showed anti-proliferative activity on hSSTR5 cells line it only showed limited decrease in cell proliferation of hSSTR2 expressing cells, but this effect did not reach 

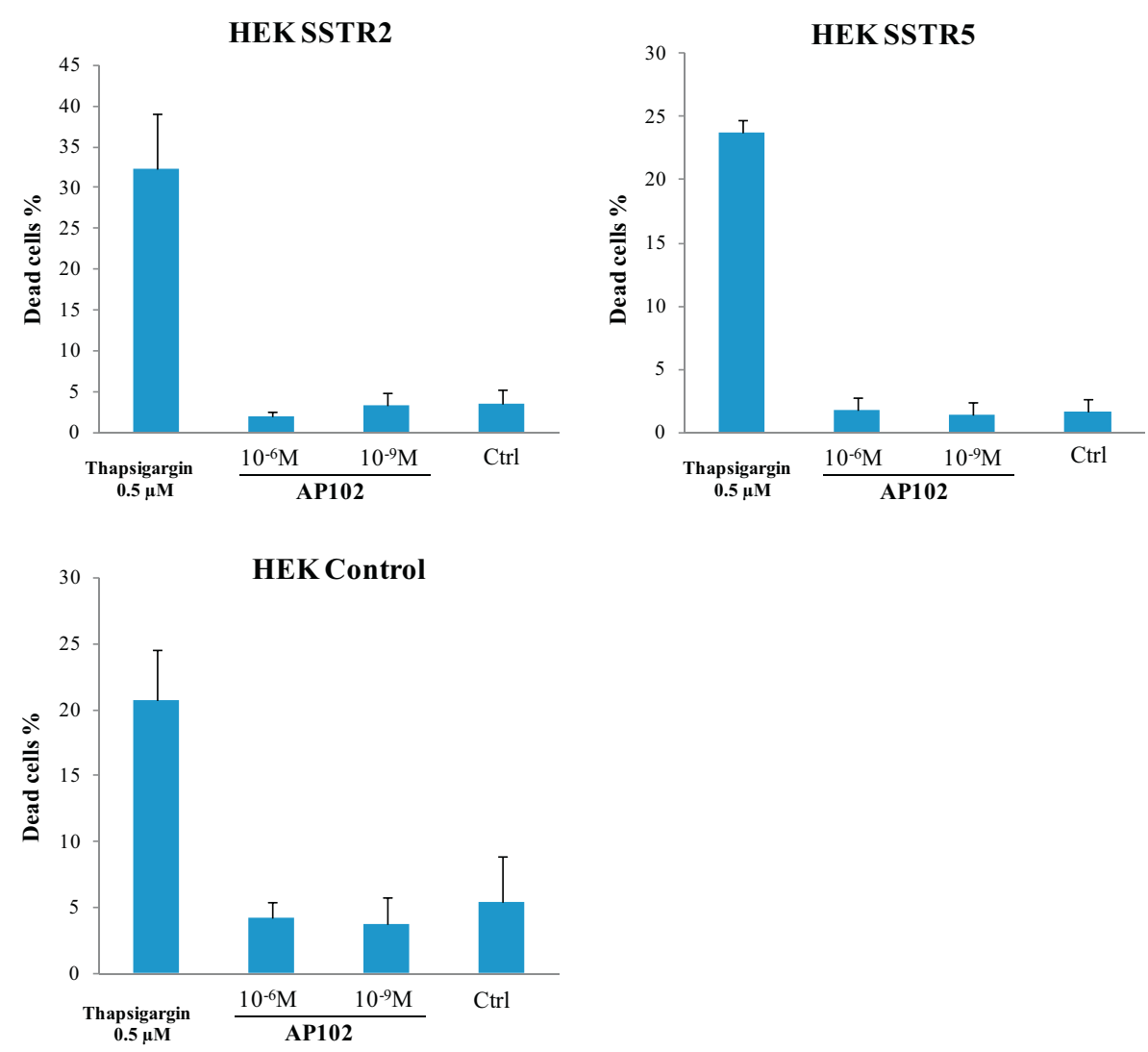

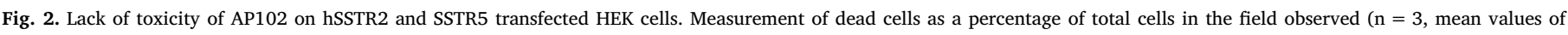
independent experiments).

Table 3

Summary of IC50's somatostatin-14 (SS14), AP102, pasireotide and octreotide with confidence intervals based on 3 to 5 separate experiments performed in duplicate using 9 concentrations of ligand. Binding curves were constructed using data derived from HEK cells expressing hSSTR2 and hSSTR5.

\begin{tabular}{llllll}
\hline & \multicolumn{3}{l}{ SSTR2 } & & \multicolumn{2}{l}{ SSTR5 } & \\
\cline { 2 - 3 } \cline { 5 - 6 } & $\begin{array}{l}\text { IC50 } \\
\text { (pM) }\end{array}$ & $\begin{array}{l}\text { 95\% confidence } \\
\text { intervals (pM) }\end{array}$ & & IC50 (pM) & $\begin{array}{l}\text { 95\% confidence } \\
\text { intervals (pM) }\end{array}$ \\
\hline SS14 & 112 & 82 to 153 & & 350 & 223 to 547 \\
AP102 & 283 & 192 to 417 & & 773 & 484 to 1234 \\
Octreotide & 244 & 124 to 481 & & 16,737 & 11,793 to 23,755 \\
Pasireotide & 3110 & 1982 to 4882 & & 200 & 114 to 347 \\
\hline
\end{tabular}

statistical significance. The lack of statistically significant effect of octreotide on hSSTR2 cells appears counter-intuitive, especially as the affinity of octreotide on hSSTR2 is higher than on hSSTR5 (244 pM and $16,737 \mathrm{pM}$, respectively). However, octreotide has been shown to have poor anti-proliferative effects in different in vitro studies (Moreno et al., 2008; Georgieva et al., 2010). Furthermore pasireotide and octreotide seem to stimulate distinct patterns of hSSTR2 phosphorylation leading to different receptor internalization and recycling mechanisms (Pöll et al., 2010; Mohamed et al., 2014). The effects of AP102 on phosphorylation patterns at SSTR2 remain to be studied in specific experiments, but it will be of interest to determine whether they differ from those of existing SSAs at both SSTR2 and SSTR5. Finally, the inhibition of cell proliferation mediated by hSSTR2 and hSSTR5 seems to occur, at least partially, via direct and indirect mechanisms (Buscail et al., 1995; Bousquet et al., 2001). AP102 behavior in vitro is distinct from pasireotide and octreotide and reveals new insights into the biology of the inhibitory effects of SS14. In a healthy rat model AP102 was recently shown to exhibit a neutral effect on blood glucose via a moderate inhibition of insulin release (SSTR5 mediated effect) paired with an inhibition of glucagon release (SSTR2 mediated effect), and potential enhancement of insulin action resulting from uninhibited GLP-1 levels (Tarasco et al., 2017). In contrast, pasireotide is more potent on SSTR2 and less potent on SSTR5 than AP102 and is the most likely mechanism for inducing hyperglycaemia. More recent preliminary data compared AP102 and pasireotide directly in a model of metabolic impairment/ diabetes, using Zucker diabetic fed rats (Daly and Sumeray, 2017). During 14 days of treatment with AP102 or pasireotide at a daily per kilogram dosing regimen that was designed to model clinical dosing in humans, AP102 had no effect on blood glucose or food/water intake. In contrast, pasireotide at the same dose led to increased blood glucose throughout the study, and both food and water intake were significantly higher than with AP102 from the first days of the study. These data further suggest that glucose balance is not impacted by AP102 in in vivo models. The lack of impact on glucose in diabetic rats may be of importance for the human setting of acromegaly where glucose impairment is common (Petrossians et al., 2017); human studies of AP102 are still awaited. The efficacy of AP102 on GH from ex vivo hypophyseal explants by Moore et al. (2005) was confirmed in animals where a single treatment with AP102 was able to reduce GH levels (Tarasco et al., 2017). However, in contrast to AP102, pasireotide binds with high affinity to SSTR3 and SSTR1 (Bruns et al., 2002), so the role of these receptors in hyperglycaemia needs to be considered. In conclusion, AP102 is a novel SSAs with a distinct SSTR2 and SSTR5 affinity profile as compared to octreotide and pasireotide. This profile has an interesting clinical potential given that AP102 may be able to maintain higher octreotide-like SSTR2 related effects than pasireotide while avoiding the inhibitory effects on insulin secretion and diabetogenic activity of pasireotide. Future clinical studies will establish whether this receptor specificity pattern seen with AP102 will translate into a better clinical efficacy and tolerability profile. 


\section{Acknowledgments}

We are grateful to Dr. John Watson for scientific comments received during the conduct of the project.

\section{Funding}

This study was funded by a grant from the Swiss Confederation, (Commission for Technology and Innovation (CTI) http://www. ctistartup.ch). Nr. 15808.1 PFLS-LS and Amryt Pharmaceuticals.

\section{Disclosure statement}

Dr. Eric Grouzmann, Dr. Alan G Harris and Dr. Adrian F. Daly disclosed consulting or stock ownership relationships with Amryt Pharmaceuticals, the developer of AP102.

\section{Appendix A. Supplementary data}

Supplementary data to this article can be found online at https:// doi.org/10.1016/j.npep.2018.02.005.

\section{References}

Allagnat, F., Klee, P., Cardozo, A.K., Meda, P., Haefliger, J.A., 2013 Dec. Connexin36 contributes to INS-1E cells survival through modulation of cytokine-induced oxidative stress, ER stress and AMPK activity. Cell Death Differ. 20 (12), 1742-1752. http://dx.doi.org/10.1038/cdd.2013.134.

Bousquet, C., Puente, E., Buscail, L., et al., 2001. Antiproliferative effect of somatostatin and analogs. Chemotherapy 47 (Suppl. 2), 30-39.

Bruns, C., Lewis, I., Briner, U., Meno-Tetang, G., Weckbecker, G., 2002. SOM230: a novel somatostatin peptidomimetic with broad somatotropin release inhibiting factor (SRIF) receptor binding and a unique antisecretory profile. Eur. J. Endocrinol. 146 (5), 707-716.

Buscail, L., Estève, J.P., Saint-Laurent, N., et al., 1995. Inhibition of cell proliferation by the somatostatin analogue RC-160 is mediated by somatostatin receptor subtypes SSTR2 and SSTR5 through different mechanisms. Proc. Natl. Acad. Sci. U. S. A. 92 (5), 1580-1584.

Colao, A., Auriemma, R.S., Pivonello, R., 2016 Apr. The effects of somatostatin analogue therapy on pituitary tumor volume in patients with acromegaly. Pituitary 19 (2), 210-221. http://dx.doi.org/10.1007/s11102-015-0677-y.

Csaba, Z., Dournaud, P., 2001 Feb. Cellular biology of somatostatin receptors. Neuropeptides 35 (1), 1-23 (Review).

Daly, A.F., Sumeray, M., 2017. The dual SSTR2/5 specific somatostatin analog, AP102, does not affect glucose metabolism in diabetic ZDF rats: a comparative 14-day infusion study versus pasireotide. In: 15th International Pituitary Congress, Orlando, USA, March 29-31, (Abstract HT1).

Eigler, T., Ben-Shlomo, A., 2014 Aug. Somatostatin system: molecular mechanisms regulating anterior pituitary hormones. J. Mol. Endocrinol. 53 (1), R1-19. http://dx.doi. org/10.1530/JME-14-0034.

Eisenhofer, G., Tischler, A.S., de Krijger, R.R., 2012 Mar. Diagnostic tests and biomarkers for pheochromocytoma and extra-adrenal paraganglioma: from routine laboratory methods to disease stratification. Endocr. Pathol. 23 (1), 4-14. http://dx.doi.org/10. 1007/s12022-011-9188-1.

Franscini, L.C., Vazquez-Montes, M., Buclin, T., Perera, R., Dunand, M., Grouzmann, E., Beck-Popovic, M., 2015 Apr. Pediatric reference intervals for plasma free and total metanephrines established with a parametric approach: relevance to the diagnosis of neuroblastoma. Pediatr. Blood Cancer 62 (4), 587-593. http://dx.doi.org/10.1002/ pbc. 25385.

Georgieva, I., Koychev, D., Wang, Y., et al., 2010. ZM447439, a novel promising aurora kinase inhibitor, provokes antiproliferative and proapoptotic effects alone and in combination with bio- and chemotherapeutic agents in gastroenteropancreatic neuroendocrine tumor cell lines. Neuroendocrinology 91 (2), 121-130.

Grant, M., Alturaihi, H., Jaquet, P., Collier, B., Kumar, U., 2008 Oct. Cell growth inhibition and functioning of human somatostatin receptor type 2 are modulated by receptor heterodimerization. Mol. Endocrinol. 22 (10), 2278-2292.

Katznelson, L., Laws Jr., E.R., Melmed, S., Molitch, M.E., Murad, M.H., Utz, A., Wass, J.A., 2014 Nov. Endocrine society acromegaly: an endocrine society clinical practice guideline. J. Clin. Endocrinol. Metab. 99 (11), 3933-3951. http://dx.doi.org/10. 1210/jc.2014-2700.

Körner, M., 2016 Jan. Specific biology of neuroendocrine tumors: peptide receptors as molecular targets. Best Pract. Res. Clin. Endocrinol. Metab. 30 (1), 19-31. http://dx. doi.org/10.1016/j.beem.2016.01.001.

Lesche, S., Lehmann, D., Nagel, F., Schmid, H.A., Schulz, S., 2009 Feb. Differential effects of octreotide and pasireotide on somatostatin receptor internalization and trafficking in vitro. J. Clin. Endocrinol. Metab. 94 (2), 654-661. http://dx.doi.org/10.1210/jc. 2008-1919.

McKeage, K., 2015 Jun. Pasireotide in acromegaly: a review. Drugs 75 (9), 1039-1048. http://dx.doi.org/10.1007/s40265-015-0413-y.

Modlin, I.M., Bodei, L., Kidd, M., 2016 Jan. Neuroendocrine tumor biomarkers: from monoanalytes to transcripts and algorithms. Best Pract. Res. Clin. Endocrinol. Metab. 30 (1), 59-77. http://dx.doi.org/10.1016/j.beem.2016.01.002.

Mohamed, A., Blanchard, M.P., Albertelli, M., et al., 2014. Pasireotide and octreotide antiproliferative effects and sst2 trafficking in human pancreatic neuroendocrine tumor cultures. Endocr. Relat. Cancer 21 (5), 691-704.

Moore, S.B., van der Hoek, J., de Capua, A., van Koetsveld, P.M., Hofland, L.J., Lamberts, S.W., Goodman, M., 2005 Oct 20. Discovery of iodinated somatostatin analogues selective for hsst2 and hsst5 with excellent inhibition of growth hormone and prolactin release from rat pituitary cells. J. Med. Chem. 48 (21), 6643-6652 (PMID: 16220980).

Moreno, A., Akcakanat, A., Munsell, M.F., et al., 2008. Antitumor activity of rapamycin and octreotide as single agents or in combination in neuroendocrine tumors. Endocr. Relat. Cancer 15 (1), 257-266.

Öberg, K., Lamberts, S.W., 2016 Dec. Somatostatin analogues in acromegaly and gastroenteropancreatic neuroendocrine tumours: past, present and future. Endocr. Relat. Cancer 23 (12), R551-R566.

Paragliola, R.M., Corsello, S.M., Salvatori, R., 2017 Feb. Somatostatin receptor ligands in acromegaly: clinical response and factors predicting resistance. Pituitary 20 (1), 109-115. http://dx.doi.org/10.1007/s11102-016-0768-4.

Peng, Y., Deng, L., Ding, Y., Chen, Q., Wu, Y., Yang, M., Wang, Y., Fu, Q., 2014 Feb 27. Comparative study of somatostatin-human serum albumin fusion proteins and natural somatostatin on receptor binding, internalization and activation. PLoS One 9 (2).

Petrossians, P., Daly, A.F., Natchev, E., et al., 2017 Oct. Acromegaly at diagnosis in 3173 patients from the Liège Acromegaly Survey (LAS) Database. Endocr. Relat. Cancer 24 (10), 505-518. http://dx.doi.org/10.1530/ERC-17-0253.

Pöll, F., Lehmann, D., Illing, S., et al., 2010. Pasireotide and octreotide stimulate distinct patterns of sst2A somatostatin receptor phosphorylation. Mol. Endocrinol. 24 (2), $436-446$.

Schmid, H.A., Schoeffter, P., 2004. Functional activity of the multiligand analog SOM230 at human recombinant somatostatin receptor subtypes supports its usefulness in neuroendocrine tumors. Neuroendocrinology 80 (Suppl. 1), 47-50.

Silverstein, J.M., 2016 Oct. Hyperglycemia induced by pasireotide in patients with Cushing's disease or acromegaly. Pituitary 19 (5), 536-543. http://dx.doi.org/10. 1007/s11102-016-0734-1.

Tarasco, E., Seebeck, P., Pfundstein, S., Daly, A.F., Eugster, P.J., Harris, A.G., Grouzmann, E., Lutz, T.A., Boyle, C.N., 2017 Aug 18. Effect of AP102, a subtype 2 and 5 specific somatostatin analog, on glucose metabolism in rats. Endocrine. http://dx.doi.org/10. 1007/s12020-017-1386-2

Theodoropoulou, M., Stalla, G.K., 2013 Aug. Somatostatin receptors: from signaling to clinical practice. Front. Neuroendocrinol. 34 (3), 228-252. http://dx.doi.org/10. 1016/j.yfrne.2013.07.005. 